\title{
Surface sensitivity in scanning transmission x-ray microspectroscopy using secondary electron detection
}

\author{
C. Hub,${ }^{1}$ S. Wenzel, ${ }^{1}$ J. Raabe, ${ }^{2}$ H. Ade ${ }^{3}$ and R. H. Fink ${ }^{1}$ \\ ${ }^{1}$ Physikalische Chemie II and ICMM, Universität Erlangen-Nürnberg, 91058 Erlangen, Germany \\ ${ }^{2}$ Swiss Light Source, Paul Scherrer Institut, 5232 Villigen-PSI, Switzerland \\ ${ }^{3}$ Department of Physics, North Carolina State University, Raleigh, North Carolina 27695-8202, USA
}

(Received 19 December 2009; accepted 19 February 2010; published online 19 March 2010)

\begin{abstract}
The successful integration of electron detection into an existing scanning transmission x-ray microspectroscope (STXM) at the Swiss Light Source is demonstrated. In conventional X-ray detection using a photomultiplier, STXM offers mainly bulk sensitivity combined with high lateral resolution. However, by implementation of a channeltron electron multiplier, the surface sensitivity can be established by the detection of secondary electrons emitted from the sample upon resonant excitation. We describe the experimental setup and discuss several relevant aspects, in particular the schemes to correct for self-absorption in the specimen due to back illumination in case of thicker films. (ㅇ) 2010 American Institute of Physics. [doi:10.1063/1.3360813]
\end{abstract}

\section{INTRODUCTION}

Scanning transmission X-ray microspectroscopy (STXM) is a well established powerful technique to investigate the quantitatiailve, spatially resolved composition of an ultrathin sample using the distinct spectral features in $\mathrm{x}$-ray absorption. ${ }^{1}$ The wide field of applications has been demonstrated so far, by the investigation of various biomaterials, ${ }^{2,3}$ environmental, ${ }^{4,5}$ geological, ${ }^{6-9}$ magnetic, ${ }^{10}$ meteoritic, ${ }^{11-13}$ technologically relevant, ${ }^{14}$ and polymeric specimens. ${ }^{10,15}$ Soft $\mathrm{x}$-rays in the energy regime from $100-1000 \mathrm{eV}$ are wellsuited to excite core electrons into unoccupied states thus probing the chemical state of the element under investigation. The valuable spectroscopic contrast has been proven in the field of polymers and soft matter samples, i.e., mainly for $\mathrm{C}$ 1s absorption. In these cases the manifold of unoccupied molecular states is probed with high spectral accuracy. ${ }^{16,17}$

STXM combines the high spectral sensitivity with very high lateral resolution thus allowing correlations of morphological and electronic or chemical properties. At present, several instruments operating in the soft $\mathrm{x}$-ray regime are installed at various synchrotron facilities. ${ }^{18-23}$ In the soft $\mathrm{x}$-ray regime Fresnel zone plates (FZPs) are most commonly used as focusing optical element. The sample of appropriate thickness is raster-scanned across the focal spot. Usually the transmitted x-ray intensity is monitored by a photomultiplier or photodiode mounted behind the sample. Therefore, the technique must be considered to be mostly bulk-sensitive. However, as for every transmission technique the samples under investigation are limited to a certain thickness range due to $\mathrm{S} / \mathrm{N}$ considerations. The signal, i.e., the measured optical density (OD) of a sample, is the log ratio of incident $\left(\mathrm{I}_{0}\right)$ to transmitted intensity (I), i.e., $\mathrm{OD}=-\ln \mathrm{I} / \mathrm{I}_{0}=\ln \mathrm{I}_{0} / \mathrm{I}$. Hence, the noise is not simply the variance of the number of absorbed photons given by Poisson statistics. In the limit of $\mathrm{I}=\mathrm{I}_{0}$ intensity, this $\log$ ratio yields a signal of zero. Similarly, for very large absorption, the photon shot noise of I approaches infinity, and $\mathrm{S} / \mathrm{N}$ is again very small. Considering error propagation of OD, the optimum sample thickness in the absence of dark noise and background corresponds to a sample with an OD of 2.6. In practice, spectral contamination and background noise can lead to absorption saturation, resulting in optimum sample thickness in the range of 1 to 2 OD. For most carbonaceous samples investigated near the carbon absorption edge, this corresponds to a practical sample thickness of 100-200 nm. Samples thinner than the OD optimum of $\sim 250 \mathrm{~nm}$, lead invariably to poor $\mathrm{S} / \mathrm{N}$. This is a principle limitation of STXM.

Surface sensitivity in soft $\mathrm{x}$-ray microspectroscopy is achieved in $\mathrm{x}$-ray photoelectron emission microscopy (XPEEM) due to the limited inelastic mean free path of the photo- or secondary electrons which generate the twodimensional image. Thus XPEEM offers complementary information to STXM. In order to enhance surface sensitivity in zone-plate based microspectroscopy electron yield detection is required, however, spatial restrictions limit the implementation of an electron detector from the illumination side. Although zone-plate based scanning photoemission microscopy has been successfully developed, ${ }^{24-27}$ its application is still rather scarce, whereas conventional STXM is growing in interest.

In the present paper, we report on expanding the capabilities of the PolLux-STXM installed at the Swiss Light Source (SLS) (Villigen/Switzerland) with the implementation of a channeltron detector downstream of the sample. The channeltron can serve as both x-ray and electron detector or can be used simultaneously with the existing photomultiplier tube (PMT), thus combining surface and bulk sensitivity in one instrument. This principle has been proven earlier for ultrathin metallic bilayer samples at the Canadian Light Source. ${ }^{28}$ The present paper goes beyond this scope. The experimental setup is described in detail and the advantages and limitations of the principle are discussed. Its emphasis is on the relevant issues such as, e.g., sensitivity or selfabsorption within the sample of thicker films. The results are 

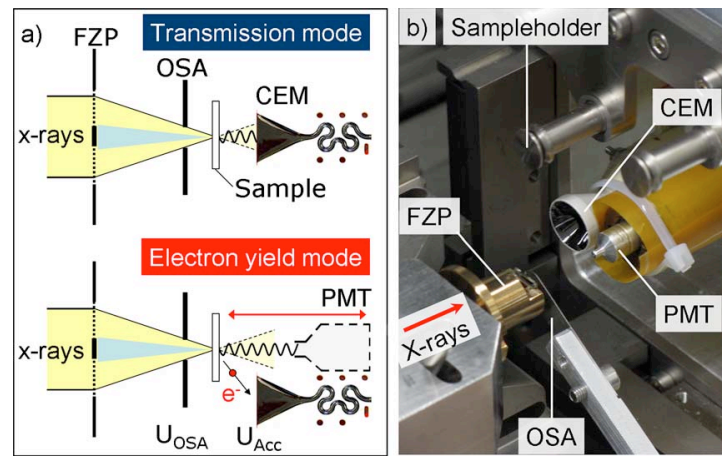

FIG. 1. (Color online) (a) Scheme using a CEM for the detection of transmitted x-ray photons or secondary electrons in STXM and (b) the corresponding photograph of the PolLux microscope with the simultaneous detection setup is shown. Depending on the position of the detector directly behind the sample, the microscope can be operated either in transmission mode, probing the transmitted x-ray intensity, or in electron yield mode, detecting the emitted secondary electrons. To collect sufficient electrons, an acceleration voltage $\left(\mathrm{U}_{\mathrm{acc}}\right)$ of $100 \mathrm{~V}$ was applied to the entrance cone of the channeltron and a bias of $50 \mathrm{~V}$ to the OSA $\left(\mathrm{U}_{\mathrm{OSA}}\right)$ to minimize the electron background signal.

discussed in view of prior XPEEM experiments to exemplify the modified detection scheme complementary to conventional STXM.

\section{EXPERIMENTAL SETUP AND SAMPLE PREPARATION}

In the present PolLux microspectroscope, the x-ray beam is focused by a FZP and higher diffraction orders are filtered by an order-sorting aperture (OSA) $(50 \mu \mathrm{m}$ pinhole). The samples are prepared on a semitransparent silicon nitride membrane or on a transmission electron microscopy grid and are raster-scanned in the focal plane. Until now, only photon sensitive detectors have been installed in the PolLux-STXM. ${ }^{23}$ In our current experiments, electron detection has been implemented to extend the scope of operation to ultrathin samples. In addition, an enhanced surface sensitivity to thicker specimens, due to the short inelastic mean free path of low energy electrons within matter, is achieved. Nevertheless the addressable range in sample thickness is still limited by the absorption saturation $(<150 \mathrm{~nm}$ in many cases). To the previous PMT of the PolLux STXM a channeltron electron multiplier (CEM) (Sjuts, KBL 10RS, typical amplification factor: $10^{7}-10^{8}$ ), as shown in Fig. 1(b), has been added. The distance of the channeltron detector is variable and was found to be at an optimum position $6 \mathrm{~mm}$ behind the sample plane. Since the CEM is sensitive to electrons as well as to $\mathrm{x}$ rays, the detector can be operated in two different modes. Identical results as in standard STXM are achieved when the detector is operated in transmission mode, i.e., the detector is placed directly behind the sample in the on-axis geometry [Fig. 1(a), top] and the transmitted photon intensity is recorded similar to standard STXM with a PMT. Moving the detector in the "off"-axis position, i.e., outside the x-ray cone of the ZP/OSA assembly, one can switch to total electron yield (TEY) detection [Fig. 1(a), bottom]. In that case the transmitted photons can be detected by the PMT simultaneously. Further considerations due to the low free mean path of the electrons are necessary; (i) in order that the emitted electrons can be detected the investigated sample surface must point toward the detector, and (ii) since the electron detector is in off-axis position a positive accelerating potential $\mathrm{U}_{\text {acc }}$ of $100 \mathrm{~V}$ has to be applied to the entrance cone of the channeltron to collect a sufficient fraction of the emitted electrons. To minimize the detection of electrons generated by the x-ray beam impacting the front of the sample, a bias of $50 \mathrm{~V}\left(\mathrm{U}_{\mathrm{OSA}}\right)$ was applied to the OSA to extract the corresponding electrons. This also minimizes the signal background from electrons generated elsewhere, such as the zone plate and the edges of the OSA. To enhance the signal quality and to preserve the channeltrons sensitive detection layer, a low pressure $\left(\mathrm{p}<1 \times 10^{-6} \mathrm{mbar}\right)$ within the measuring chamber is essential.

Two test samples spanning the thin and thick sample limits were investigated in order to test the performance of the new detector setup. A $5 \mathrm{~nm}$ thick pentacene film was used to demonstrate the power of the new detector setup with respect to ultrathin and low absorbing specimens. A $100 \mathrm{~nm}$ thick PS/PMMA polymer blend was chosen to investigate the advantages of the new detector setup with respect to surface sensitivity enhancement in thicker samples. The polystyrene/poly(methyl methacrylate) (PS/PMMA) is a model polymer system to explore the chemical sensitivity of NEXAFS microscopy. It has been well studied previously with STXM and XPEEM. ${ }^{29-31}$

The pentacene film was deposited on a commercially available silicon nitride membrane (Silson Ltd., $100 \mathrm{~nm}$ ) under high vacuum conditions $\left(\mathrm{p}<5 \times 10^{-7} \mathrm{mbar}\right)$. Prior to deposition commercial pentacene (Sigma Aldrich, purity $99.9+\%)$ was further cleaned by resublimation in vacuum twice. The film thickness was controlled in situ with a quartz microbalance and was confirmed by atomic force microscopy afterwards.

The polymer test sample was prepared by spin-casting of a 1:1-mixture of PS and PMMA from toluene solution (1 wt \%) onto a silicon nitride membrane. Both homopolymers, PS (250 kDa) and PMMA (35 kDa), were used as received from Acros Organics. The sample was annealed at $170{ }^{\circ} \mathrm{C}$ for $48 \mathrm{~h}$ to facilitate the phase separation of the immiscible polymer blend toward thermodynamic equilibrium with well defined structures.

\section{RESULTS AND DISCUSSION}

Figure 2(a) shows the OD image (area: $20 \times 20 \mu \mathrm{m}^{2}$ ) of the pentacene film with a nominal thickness of $5 \mathrm{~nm}$ recorded at an excitation energy of $285.8 \mathrm{eV}$. Due to the relatively inhomogeneous nitride substrate, offering a multiplicity of nucleation sites for the organic molecules, a polycrystalline structure of the vacuum deposited pentacene film is observed. At a nominal film thickness of only $5 \mathrm{~nm}$ (corresponding to $3.3 \mathrm{ML}$ of upright standing pentacene molecules) the single grains are already coalescing and forming a closed film leaving the grain boundaries still visible. ${ }^{32}$ The single grains seem to show a random shape with a lateral extension of a few micrometers. The contrast within the images is due to thickness variations on one hand and due to the presence of different rotational domains within the indi- 

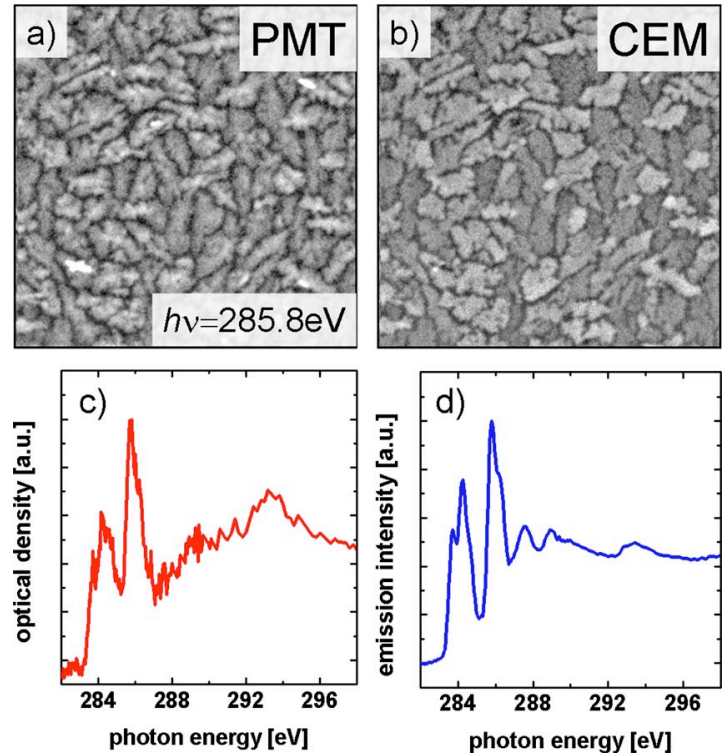

FIG. 2. (Color online) Scanning x-ray microscope images of a $5 \mathrm{~nm}$ thick pentacene film recorded in (a) using a PMT (OD in transmission mode) and in (b) using a CEM as detector (electron yield mode). The corresponding NEXAFS spectra recorded at the C K-edge are shown in (c) (PMT) and (d) (CEM), respectively.

vidual grains on the other hand. ${ }^{33}$ The direct comparison with Fig. 2(b) recorded with the CEM detector (identical recording parameters and sample area) reveals an identical contrast. Note that the film thickness corresponds by and large to the inelastic mean free path of the low energy secondary electrons, i.e., the majority of emitted electrons. Therefore, low x-ray absorption (low OD) yields low electron emission and when comparing the OD signal to the TEY images, overall identical contrast is observed.

Most importantly, improved S/N-ratio is observed in the NEXAFS spectra for e-yield detection. The evaluation of the $\mathrm{S} / \mathrm{N}$-ratio ${ }^{34}$ revealed an improvement of the signal-to-noise ratio by a factor of nearly 10 . The highly resolved NEXAFS C-K-edge spectra shown in Figs. 2(c) and 2(d) were extracted from line scans consisting of 20 points with a point density of 2 points $/ \mu \mathrm{m}$ and a dwell time of $100 \mathrm{~ms}$. To minimize the influence of potential beam damage by the high flux density of incident x-ray photons the spectra were recorded with a slightly defocused beam. Therefore the NEXAFS spectrum averages over different rotational domains. The data show the presence of various resonances in the near-edge region between $282-296 \mathrm{eV}$. In this photon energy regime the sharp resonances can be attributed to the excitation of electrons from the $\mathrm{C} 1 \mathrm{~s}$ level into unoccupied molecular orbitals $\left(\pi^{*}\right)$. Due to core-hole effects and due to the excitation out of different carbon sites (C 1s) the resonances split into different components with an intense resonance at $285.2 \mathrm{eV}$. A detailed assignment of the different resonances and a theoretical $a b$ initio calculation of pentacene thin film and gas-phase spectra can be found elsewhere. ${ }^{35-37}$ It is obvious from Figs. 2(c) and 2(d) that the spectroscopic S/Nratio can be improved drastically by the substitution of the PMT with a CEM. This difference is mainly due to the fact that e-yield detection is basically a dark field method, i.e., is not affected by a significant photon background signal. Note

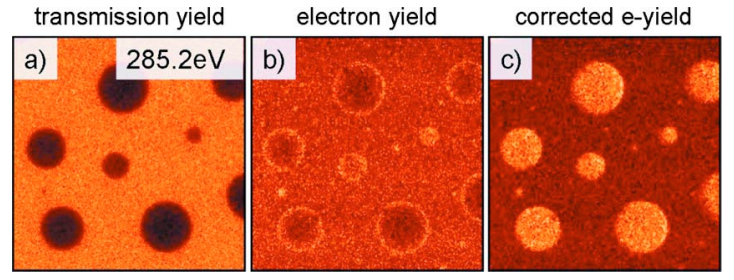

FIG. 3. (Color online) (a) STXM image of a $100 \mathrm{~nm}$ PS/PMMA sample recorded with an excitation energy of $285.2 \mathrm{eV}$ (a) in transmission mode, (b) in electron yield mode, and (c) the self-absorption corrected electron yield mode, corresponding to a division of image (b) by image (a).

that in the thin film limit, the absorption signal is extracted from the small relative reduction in an intense photon signal as discussed above. The OD of the sample of 0.06 is much smaller than the optimum OD of 2.6 and corresponds to a reduction in intensity of around $10 \%$.

While the interpretation of ultrathin film TEY images ( $d \leq$ inelastic mean free path of electrons) is quite trivial, more efforts are required to interpret the surface signal of thicker films using e-yield STXM. This is demonstrated with the PS/PMMA polymer blend test sample. The characteristic phase separated structures of PS in the PMMA matrix are observed in the scanning x-ray micrographs of Fig. $3 .^{38}$ The images were recorded at a photon energy of $285.2 \mathrm{eV}$, corresponding to the $\pi^{*} \mathrm{C}=\mathrm{C}$ transition in PS, which corresponds to the strongest absorption resonance of PS. ${ }^{38}$ Since the onset of absorption in PMMA occurs for $\mathrm{h} \nu \geq 286.5 \mathrm{eV}$, an exclusive absorption of the polystyrene within the polymer blend sample can be achieved. The transmission image in Fig. 3(a) nicely resolves the contrast between the highly absorbing PS droplets (dark) within the weakly absorbing PMMA matrix (bright). The direct evaluation of the image recorded in electron yield mode in Fig. 3(b) is not trivial. A first look shows that obviously the smaller PS droplets and the outer regions of the larger PS droplets show higher electron emission (brighter) than the center of the PS containing regions.

When using electrons as detection probe, the investigated film is oriented toward the electron detector, i.e., we have to illuminate the specimen from the back side. Consequently the damping of the intensity due to the absorption within the film (which does not contribute to electron emission) has to be considered.

For a better understanding the phenomenon of selfabsorption within the film shall be discussed first for an ideal bilayer system consisting of components A and B according to Fig. 4(a). In case of electron detection only electrons emitted out of a surface-near region with the thickness $d_{e}$ can be detected due to the low mean free path of the electrons. The incident intensity $\mathrm{I}_{0}$, which depends on the photon energy due to absorption at the various optical elements (mirror, grating, vacuum window, and zone plate), is damped through inelastic processes within the sample to the intensity $\mathrm{I}_{0}^{\prime}$ that reaches the electron emission layer. According to the Lambert-Beer law the degree of damping is determined by the thickness of the transmitted film $\left(\mathrm{d}_{\mathrm{A}}, \mathrm{d}_{\mathrm{B}}\right)$ and their corresponding photon-energy dependant absorption coefficients 

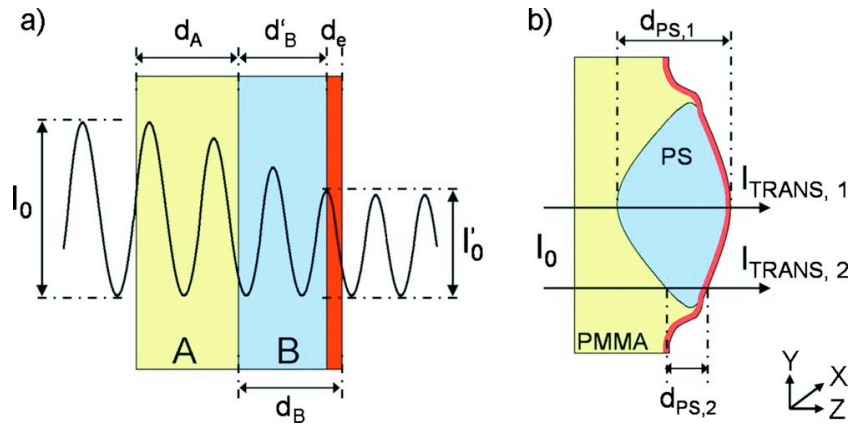

FIG. 4. (Color online) Schemes of an ideal bilayer system (a) and of our more complex PS/PMMA blend (b). Local thickness and compositional variations need to be considered in the investigated polymer blend. For both cases the self-absorption needs to be taken into account.

$\left(\mu_{\mathrm{A}}, \mu_{\mathrm{B}}\right)$. Neglecting the homogenous background of the $\mathrm{Si}_{3} \mathrm{~N}_{4}$ substrate the following equation is valid for the ideal bilayer system depicted in Fig. 4(a):

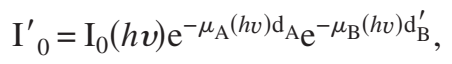

with $\mathrm{d}_{\mathrm{B}}^{\prime}=\mathrm{d}_{\mathrm{B}}-\mathrm{d}_{\mathrm{e}}, \mu_{\mathrm{Si}_{3} \mathrm{~N}_{4}}, \mathrm{~d}_{\mathrm{Si}_{3} \mathrm{~N}_{4}}$ is neglected and considered to be homogenous over whole sample.

In case of more complex morphologies such as the present PS/PMMA system [see schematic and nomenclature in Fig. 4(b)], the evaluation becomes more complicated. The binary film system consists of a mixture of materials with different absorption coefficients and local thickness variations. The thickness modulations lead to a position depending damping of the incident photon intensity $\mathrm{I}_{0}^{\prime}$. Therefore the local thickness $\left(\mathrm{d}_{\mathrm{i}}\right)$ and the corresponding absorption coefficient $\left(\mu_{\mathrm{i}}\right)$ for each spot $(\mathrm{x}, \mathrm{y})$ must be considered. However the thickness of the electron emitting layer is in the range of a few nanometers only. Neglecting the continuous self-absorption within this thin layer, the transmitted intensity represents a good approximation of the damped intensity $\mathrm{I}_{0}^{\prime}$. Depending on the composition of the electron emitting layer $\left[\mathrm{d}_{\mathrm{i}, \mathrm{e}}(\mathrm{x}, \mathrm{y})\right]$ (for PS and/or PMMA) the equation needs to be adapted accordingly.

$$
\begin{aligned}
\mathrm{I}_{0}^{\prime}(\mathrm{x}, \mathrm{y}) & \approx \mathrm{I}_{\mathrm{TRANS}}(\mathrm{x}, \mathrm{y}) \\
& =\mathrm{I}_{0}(h v) \mathrm{e}^{-\mu_{\mathrm{PMMA}}(h v) \mathrm{d}_{\mathrm{PMMA}}(\mathrm{x}, \mathrm{y})} \mathrm{e}^{-\mu_{\mathrm{PS}}(h v) \mathrm{d}_{\mathrm{PS}}(\mathrm{x}, \mathrm{y})} \mathrm{e}^{\mu_{\mathrm{i}}(h v) \mathrm{d}_{\mathrm{i}}^{\prime}(\mathrm{x}, \mathrm{y})},
\end{aligned}
$$

with $\mathrm{d}_{\mathrm{i}}^{\prime}=\mathrm{d}_{\mathrm{i}}-\mathrm{d}_{\mathrm{i}, \mathrm{e}}$, (i=PS and/or PMMA)

As result, the intensity of the emitted electrons becomes proportional to the photon intensity which reaches the surface-near layer.

$\mathrm{I}_{\mathrm{e}}(\mathrm{x}, \mathrm{y}) \sim \mathrm{I}_{\text {TRANS }}(\mathrm{x}, \mathrm{y}) \mu_{\mathrm{i}} \mathrm{d}_{\mathrm{i}, \mathrm{e}}(\mathrm{x}, \mathrm{y}) \quad(\mathrm{i}=\mathrm{PS}$ and/or PMMA $)$.

Therefore we have to correct for the self-absorption in the e-yield STXM to obtain similar information to conventional XPEEM. Since the transmission image obtains the information of the overall absorption within the film, we may use this information to approximate the self-absorption, i.e., division of the electron yield image by the transmission image results in a self-absorption corrected image. The corresponding result of the correction is presented in Fig. 3(c). Since this image is corrected for the local thickness modulations and self-absorption, a homogenous emission over the whole PS droplet within a weak emitting PMMA matrix is observed. Although this simple correction scheme reflects the qualitative agreement with XPEEM, a quantitative analysis with respect to the composition remains difficult. However, the same holds for XPEEM since the electron yield can hardly be quantified. Neither in conventional XPEEM, i.e., without energy filter, nor in the present electron yield STXM the exact kinetic energy determination for the emitted electrons is impossible. In contrast to XPEEM, however, we may state that the detection efficiency in electron yield STXM is much higher. This is due to the fact that in XPEEM only a fraction of secondary electrons is used for image formation. Comparing identical spatial resolutions of few 10 nanometers standard XPEEM accepts only a few milliradian electron emission angle. ${ }^{39}$ In contrast, electron yield STXM detects all secondary electrons emitted from the sample surface by applying a positive accelerating voltage at the CEM front end thus leading to higher overall electron collection efficiencies compared to XPEEM.

\section{SUMMARY AND CONCLUSIONS}

We have demonstrated that e-yield STXM combines high spatial resolution with enhanced sensitivity to ultrathin and low absorbing samples. An improved S/N-ratio with respect to the recorded spectra has been achieved for the prototype study of a pentacene film with a nominal thickness of only $5 \mathrm{~nm}$. In addition, electron detection shows enhanced surface sensitivity for thicker films (PS/PMMA blend) which well corresponds to XPEEM micrographs. The discussed correction for self-absorption in the back-illuminated sample qualitatively corresponds to the purely surface-sensitive XPEEM results. ${ }^{29}$

The implementation of electron yield detection in STXM offers an obvious advantage compared to XPEEM if both detectors, PMT and CEM, are operated simultaneously in the STXM. The bulk information recorded with the standard PMT in the on-axis geometry can be combined with additional surface information received from the electron detection with the CEM mounted in the off-axis geometry. The implementation of both detectors might only be limited due to potential spatial restrictions in existing STXMs and potential limitations with respect to their base vacuum.

\section{ACKNOWLEDGMENTS}

We acknowledge financial support by the BMBF under Contract No. 05/KS7WE1. We would like to thank Dr. George Tzvetkov (Univ. Erlangen) and Dr. Ben Watts (PSI) for experimental support. One of us (C.H.) received financial support from the ICMM and thanks the Graduate School Molecular Science for support. HA supported by U.S. Department of Energy, Office of Science, Basic Energy Science, Division of Materials Science and Engineering under Contract No. DE-FG02-98ER45737. The research leading to these results has received funding from the Seventh Framework Programme of the European Community (FP7/20072013) under Grant Agreement No. 226716. 
${ }^{1}$ H. Ade, X. Zhang, S. Cameron, C. Costello, J. Kirz, and S. Williams, Science 258, 972 (1992).

${ }^{2}$ L. Li, A. P. Hitchcock, R. Cornelius, J. L. Brash, A. Scholl, and A. Doran, J. Phys. Chem. B 112, 2150 (2008).

3 J. Kirz, C. Jacobsen, and M. Howells, Q. Rev. Biophys. 28, 33 (1995).

${ }^{4}$ H. Bluhm, K. Andersson, T. Araki, K. Benzerara, G. E. Brown, J. J. Dynes, S. Ghosal, M. K. Gilles, H.-Ch. Hansen, J. C. Hemminger, A. P. Hitchcock, G. Ketteler, A. L. D. Kilcoyne, E. Kneedler, J. R. Lawrence, G. G. Leppard, J. Majzlam, B. S. Mun, S. C. B. Myneni, A. Nilsson, H. Ogasawara, D. F. Ogletree, K. Pecher, M. Salmeron, D. K. Shuh, B. Tonner, T. Tyliszczak, T. Warwick, and T. H. Yoon, J. Electron Spectrosc. Relat. Phenom. 150, 86 (2006).

${ }^{5}$ S. F. Maria, L. M. Russell, M. K. Gilles, and S. C. B. Myneni, Science 306, 1921 (2004).

${ }^{6}$ S. Bernard, K. Benzerara, O. Beyssac, N. Menguy, F. Guyot, G. E. Brown, Jr., and B. Goffé, Earth Planet. Sci. Lett. 262, 257 (2007).

${ }^{7}$ J. Miot, K. Benzerara, G. Morin, A. Kappler, S. Bernard, M. Obst, C. Férard, F. Skouri-Panet, J.-M. Guigner, N. Posth, M. Galvez, G. E. Brown, Jr., and F. Guyot, Geochim. Cosmochim. Acta 73, 696 (2009).

${ }^{8}$ G. D. Cody, R. E. Botto, H. Ade, S. Behal, M. Disko, and S. Wirick, Energy Fuels 9, 525 (1995).

${ }^{9}$ G. D. Cody, R. E. Botto, H. Ade, and S. Wirick, Int. J. Coal Geol. 32, 69 (1996).

${ }^{10}$ H. Ade and H. Stoll, Nature Mater. 8, 281 (2009).

${ }^{11}$ S. A. Sandford, J. Aleon, C. M. O’D. Alexander, T. Araki, S. Bajt, G. A. Baratta, J. Borg, J. P. Bradley, D. E. Brownlee, J. R. Brucato, M. J. Burchell, H. Busemann, A. Butterworth, S. J. Clemett, G. Cody, L. Colangeli, G. Cooper, L. D'Hendecourt, Z. Djouadi, J. P. Dworkin, G. Ferrini, H. Fleckenstein, G. J. Flynn, I. A. Franchi, M. Fries, M. K. Gilles, D. P. Glavin, M. Gounelle, F. Grossemy, C. Jacobsen, L. P. Keller, A. L. D. Kilcoyne, J. Leitner, G. Matrajt, A. Meibom, V. Mennella, S. Mostefaoui, L. R. Nittler, M. E. Palumbo, D. A. Papanastassiou, F. Robert, A. Rotundi, C. J. Snead, M. K. Spencer, F. J. Stadermann, A. Steele, T. Stephan, P. Tsou, T. Tyliszczak, A. J. Westphal, S. Wirick, B. Wopenka, H. Yabuta, R. N. Zare, and M. E. Zolensky, Science 314, 1720 (2006).

${ }^{12}$ D. Brownlee, P. Tsou, J. Aleon, C. M. O'D. Alexander, T. Araki, S. Bajt, G. A. Baratta, R. Bastien, P. Bland, P. Bleuet, J. Borg, J. P. Bradley, A. Brearley, F. Brenker, S. Brennan, J. C. Bridges, N. D. Browning, J. R. Brucato, E. Bullock, M. J. Burchell, H. Busemann, A. Butterworth, M. Chaussidon, A. Cheuvront, M. Chi, M. J. Cintala, B. C. Clark, S. J. Clemett, G. Cody, L. Colangeli, G. Cooper, P. Cordier, C. Daghlian, Z. Dai, L. D'Hendecourt, Z. Djouadi, G. Dominguez, T. Duxbury, J. P. Dworkin, D. S. Ebel, T. E. Economou, S. Fakra, S. A. J. Fairey, S. Fallon, G. Ferrini, T. Ferroir, H. Fleckenstein, C. Floss, G. Flynn, I. A. Franchi, M. Fries, Z. Gainsforth, J.-P. Gallien, M. Genge, M. K. Gilles, P. Gillet, J. Gilmour, D. P. Glavin, M. Gounelle, M. M. Grady, G. A. Graham, P. G. Grant, S. F. Green, F. Grossemy, L. Grossman, J. N. Grossman, Y. Guan, K. Hagiya, R. Harvey, P. Heck, G. F. Herzog, P. Hoppe, F. Hörz, J. Huth, I. D. Hutcheon, K. Ignatyev, H. Ishii, M. Ito, D. Jacob, C. Jacobsen, S. Jacobsen, S. Jones, D. Joswiak, A. Jurewicz, A. T. Kearsley, L. P. Keller, H. Khodja, A. L. D. Kilcoyne, J. Kissel, A. Krot, F. Langenhorst, A. Lanzirotti, L. Le, L. A. Leshin, J. Leitner, L. Lemelle, H. Leroux, M.-C. Liu, K. Luening, I. Lyon, G. MacPherson, M. A. Marcus, K. Marhas, B. Marty, G. Matrajt, K. McKeegan, A. Meibom, V. Mennella, K. Messenger, S. Messenger, T. Mikouchi, S. Mostefaoui, T. Nakamura, T. Nakano, M. Newville, L. R. Nittler, I. Ohnishi, K. Ohsumi, K. Okudaira, D. A. Papanastassiou, R. Palma, M. E. Palumbo, R. O. Pepin, D. Perkins, M. Perronnet, P. Pianetta, W. Rao, F. J. M. Rietmeijer, F. Robert, D. Rost, A. Rotundi, R. Ryan, S. A. Sandford, C. S. Schwandt, T. H. See, D. Schlutter, J. Sheffield-Parker, A. Simionovici, S. Simon, I. Sitnitsky, C. J. Snead, M. K. Spencer, F. J. Stadermann, A. Steele, T. Stephan, R. Stroud, J. Susini, S. R. Sutton, Y. Suzuki, M. Taheri, S. Taylor, N. Teslich, K. Tomeoka, N. Tomioka, A. Toppani, J. M. Trigo-Rodríguez, D. Troadec, A. Tsuchiyama, A. J. Tuzzolino, T. Tyliszczak, K. Uesugi, M. Velbel, J. Vellenga, E. Vicenzi, L. Vincze, J. Warren, I. Weber, M. Weisberg, A. J. Westphal, S. Wirick, D. Wooden, B. Wopenka, P. Wozniakiewicz, I. Wright, H. Yabuta, H. Yano, E. D. Young, R. N. Zare, T. Zega, K. Ziegler, L. Zimmerman, E. Zinner, and M. Zolensky, Science 314, 1711 (2006).

${ }^{13}$ G. D. Cody, H. Ade, C. M. O'D. Alexander, T. Araki, A. Butterworth, H.
Fleckenstein, G. Flynn, M. K. Gilles, C. Jacobsen, A. L. D. Kilcoyne, K. Messenger, S. A. Sandford, T. Tyliszczak, A. J. Westphal, S. Wirick, and H. Jabuta, Meteorit. Planet. Sci. 43, 353 (2008).

${ }^{14}$ G. Tzvetkov, B. Graf, P. Fernandes, A. Fery, F. Cavalieri, G. Paradossi, and R. H. Fink, Soft Matter 4, 510 (2008).

${ }^{15}$ A. P. Hitchcock, I. Koprinarov, T. Tyliszczak, E. G. Rightor, G. E. Mitchell, M. T. Dineen, F. Hayes, W. Lidy, R. D. Priester, S. G. Urquhart, A. P. Smith, and H. Ade, Ultramicroscopy 88, 33 (2001).

${ }^{16} \mathrm{H}$. Ade and A. P. Hitchcock, Polymer 49, 643 (2008).

${ }^{17}$ O. Dhez, H. Ade, and S. G. Urquart, J. Electron Spectrosc. Relat. Phenom. 128, 85 (2003).

${ }^{18}$ A. L. D. Kilcoyne, T. Tyliszczak, W. F. Steele, S. Fakra, P. Hitchcock, K. Franck, E. Anderson, B. Harteneck, E. G. Rightor, G. E. Mitchell, A. P. Hitchcock, L. Yang, T. Warwick, and H. Ade, J. Synchrotron Radiat. 10, 125 (2003).

${ }^{19}$ B. Kaulich, D. Bacescu, D. Cocco, J. Susini, M. Salomé, O. Dhez, C. David, T. Weitkamp, E. Di Fabrizio, S. Cabrini, G. Morrison, P. Charalambous, J. Thieme, T. Wilhein, J. Kovac, M. Podnar, and M. Kiskinova, J. Phys. IV 104, 103 (2003).

${ }^{20}$ M. Feser, M. Carlucci-Dayton, C. J. Jacobsen, J. Kirz, U. Neuhäusler, G. Smith, and B. Yu, Proc. SPIE, 3449, 19 (1998).

${ }^{21}$ K. V. Kaznatcheev, C. Karunakaran, U. D. Lanke, S. G. Urquhart, M. Obst, and A. P. Hitchcock, Nucl. Instrum. Methods Phys. Res. A 582, 96 (2007).

${ }^{22}$ G. Mitrea, J. Thieme, P. Guttmann, S. Heim, and S. Gleber, J. Synchrotron Radiat. 15, 26 (2008).

${ }^{23}$ J. Raabe, G. Tzvetkov, U. Flechsig, M. Böge, A. Jaggi, B. Sarafimov, M. G. C. Vernooij, T. Huthwelker, H. Ade, D. Kilcoyne, T. Tyliszczak, R. H. Fink, and C. Quitmann, Rev. Sci. Instrum. 79, 113704 (2008).

${ }^{24}$ H. Ade, J. Kirz, S. L. Hulbert, E. D. Johnson, E. Anderson, and D. Kern, Appl. Phys. Lett. 56, 1841 (1990).

${ }^{25}$ C.-H. Ko, H. Ade, E. Johnson, S. Hulbert, and E. Anderson, Rev. Sci. Instrum. 66, 1416 (1995).

${ }^{26}$ L. Casalis, W. Jark, M. Kiskinova, D. Lonza, P. Melpignano, D. Morris, R. Rosei, A. Savoia, A. Abrami, C. Fava, P. Furlan, R. Pugliese, D. Vivoda, G. Sandrin, F.-Q. Wei, S. Contarini, L. DeAngelis, C. Gariazzo, P. Nataletti, and G. R. Morrison, Rev. Sci. Instrum. 66, 4870 (1995).

${ }^{27}$ H. J. Shin and M. K. Lee, Nucl. Instrum. Methods Phys. Res. A 467-468, 909 (2001).

${ }^{28}$ B. M. Haines, S. Behyan, S. L. Christensen, M. Obst, D. Bertwistle, C. Karunakaran, T. Tyliszczak, and S. G. Urquhart, Canadian Light Source, Activity Report No. 2008, 154, 2008.

${ }^{29}$ C. Morin, H. Ikeura-Sekiguchi, T. Tyliszczak, R. Cornelius, J. L. Brash, A. P. Hitchcock, A. Scholl, F. Nolting, G. Appel, D. A. Winesett, K. Kasnacheyev, and H. Ade, J. Electron Spectrosc. Relat. Phenom. 121, 203 (2001).

${ }^{30}$ M. Harris, G. Appel, and H. Ade, Macromolecules 36, 3307 (2003).

${ }^{31}$ Q. Zong, Z. Li, and X. Xie, Macromol. Chem. Phys. 205, 1116 (2004).

${ }^{32}$ Additional conductance measurements (not shown here) reveal that the pentacene film coalesces to a certain extent (reasonable field effect mobility has been measured).

${ }^{33}$ C. Hub, M. Burkhardt, M. Halik, G. Tzvetkov, and R. Fink, "In-situ STXM investigations of pentacene-based OFETs during operation," J. Mater. Chem. (submitted).

${ }^{34}$ J. Stöhr, Surface Science, NEXAFS Spectroscopy (Springer, Berlin, 1992) Vol. 25.

${ }^{35}$ H. Oji, R. Mitsumoto, E. Ito, H. Ishii, Y. Ouchi, T. Yokoyama, T. Ohta, and N. Kosugi, J. Chem. Phys. 109, 10409 (1998).

${ }^{36}$ M. Alagia, C. Baldacchini, M. G. Betti, F. Bussolotti, V. Carravetta, U. Ekström, C. Mariani, and S. Stranges, J. Chem. Phys. 122, 124305 (2005).

${ }^{37}$ S. Lukas, S. Söhnchen, G. Witte, and C. Wöll, ChemPhysChem 5, 266 (2004).

${ }^{38}$ D. A. Winesett, S. Story, J. Lüning, and H. Ade, Langmuir 19, 8526 (2003).

${ }^{39}$ T. Schmidt, U. Groh, R. Fink, E. Umbach, O. Schaff, W. Engel, B. Richter, H. Kuhlenbeck, R. Schlögl, H.-J. Freund, A. M. Bradshaw, D. Preikszas, P. Hartel, R. Spehr, H. Rose, G. Lilienkamp, E. Bauer, and G. Benner, Surf. Rev. Lett. 9, 223 (2002). 